\title{
Strahlenpilz
}

\section{Fisteln in der zervikofazialen Region}

\author{
Ein 72-jähriger Patient klagt über eine nicht \\ schmerzhafte, eitrige Fistel im Halsbereich. \\ Bereits seit einigen Wochen habe er immer \\ wieder ein Druckgefühl an der linken Halsseite \\ verspürt, außerdem hatte er in unregelmäßigen \\ Abständen eine erhöhte Temperatur.
}

\section{Klinik}

Die Aktinomykose (auch bekannt als „Strahlenpilz“) ist eine seltene, subakute bakterielle Infektionskrankheit, bei der sich Granulome mit ausgeprägter Tendenz zur Fistelbildung finden. Die Granulome liegen in über 90\% der Fälle in der Zervikofazialregion (Abb. 1). Das Krankheitsbild muss vor allem bei der Differenzialdiagnose von Mundboden- und Halsabszessen, aber auch von malignen Raumforderungen bedacht werden. Klinische Unterscheidungsmerkmale zu den genannten Differenzialdiagnosen sind die häufige Fistelbildung nach außen sowie die geringe Schmerzhaftigkeit der Aktinomykose. Die Allgemeinsymptome der Aktinomykose entsprechen denen einer chronisch eitrigen Infektion (unregelmäßige Temperaturen, Nachtschweiß), deren Ausprägung entsprechend abhängig von der Ausdehnung des Befundbildes ist.

\section{Diagnostik}

Im Vordergrund steht neben der Erregersicherung die Computertomografie (Abb. 2) als bildgebendes Verfahren, um die Ausdehnung der Erkrankung einschätzen zu können.

\section{Therapie}

Das Bakterium aus der grampositiven Gruppe der Aktinomyzeten ist penicillinempfindlich, entsprechend ist Penicillin die Therapie der Wahl.

\section{Prof. Dr. med. Gerhard Grevers}

Prinzenweg

82319 Starnberg

E-Mail: Grevers@gmx.de

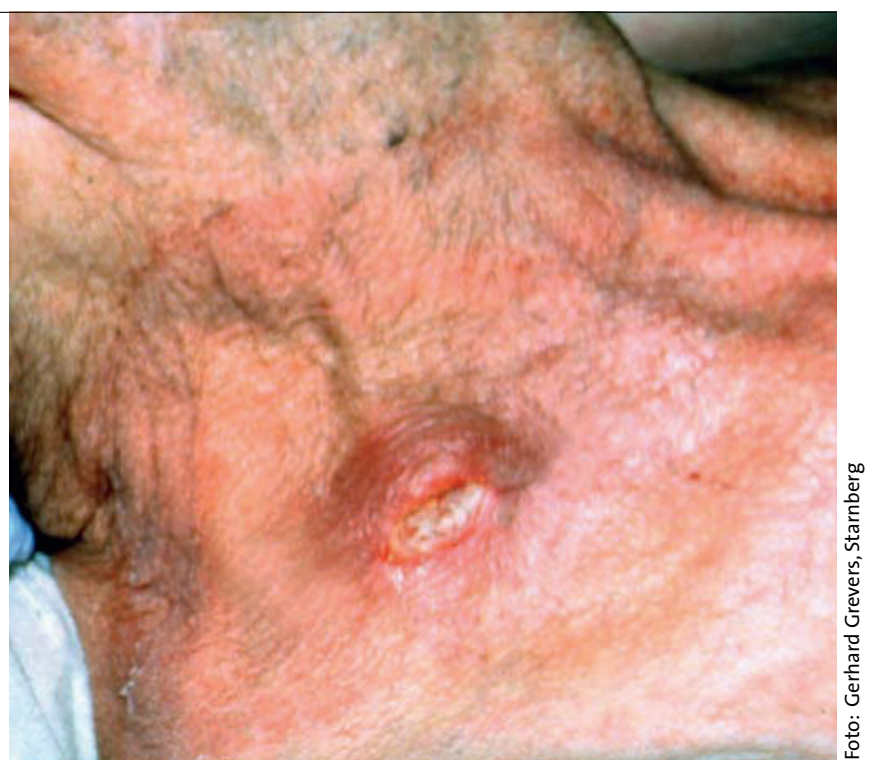

Abb. 1: Das klinische Bild zeigt eine Rötung und Fistelbildung (Pfeile) der Haut im seitlichen Halsbereich.

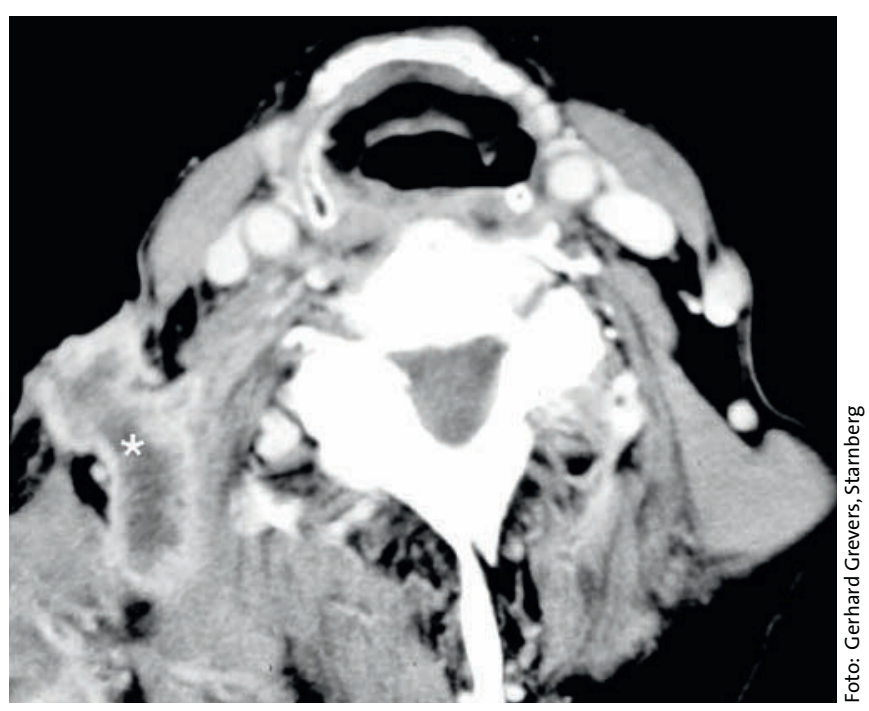

Abb. 2: Im axialen Computertomogramm zeigt sich das typische Bild eines Abszesses am Hals $\left(^{*}\right)$ mit Fistelbildung nach außen bei Aktinomykose. 